All letters are subject to editing and may be shortened. Letters should be sent to the BJGP office by e-mail in the first instance, addressed to

journal@rcgp.org.uk (please include your postal address). Alternatively, they may be sent by post as an MS Word or plain text version on CD or DVD. We regret that we cannot notify authors regarding publication. Letters not published in the Journal may be posted online on our Discussion Forum. For instructions please visit: http://www.rcgp.org.uk/bjgp-discuss

\section{Use of evidence in hypertension guidelines}

In their review of the use of evidence in hypertension guidelines, Parker and Glasziou point out that failure to measure blood pressure in both arms may lead to delay in diagnosis or inadequate treatment of high blood pressure. ${ }^{1}$ However, only $30 \%$ of GPs agree with recommendations to measure blood pressure in both arms, and even fewer actually do it. Similarly, it is important to see if patients who take their own blood pressure at home adhere to recommendations, both measuring and recording their readings correctly.

Assessing the reliability of patients' reports of home blood pressure measurements is crucial to see whether self-monitoring can be used by health professionals to provide precise estimates of the true blood pressure. ${ }^{2}$ Possible disadvantages of this technique include reporting bias and unsupervised alteration of medication. Newer blood pressure monitors offer the advantages of built-in printers or internal storage of all blood pressure measurements, which can be subsequently downloaded. ${ }^{3}$

We are completing recruitment for a Stroke Association funded trial of home blood pressure monitoring in 360 hypertensive stroke patients. ${ }^{4}$

Intervention patients are given a blood pressure monitor, shown how to use it, and asked to record their blood pressure once a week taking three readings each time. In Spring 2009 we conducted a pilot study to examine the reliability and accuracy of patients' blood pressure recordings and the degree to which patients might selectively record readings, therefore misreporting their blood pressure. We compared the actual readings downloaded from the blood pressure monitor with those recorded in the patient booklet over the previous month.

We found that most patients were recording their blood pressure accurately, and the measurements recorded were true readings. Although participants may be taking extra readings when their blood pressure was above target, there appeared to be little selectivity in the recording of blood pressure measurements. This is in line with a previous UK study from primary care. ${ }^{5}$ It suggests that stroke patients who are shown how to monitor their own blood pressure at home generally do it reliably and according to guidelines, an example that GPs who only ever take blood pressure in one arm might consider following!

\section{Yvette Adjei-Gyamfi,}

125 Briar Road, Romford, Essex, RM3 8AP.

E-mail: yagyamfi@doctors.org.uk

\section{Sally Kerry,}

Community Health Sciences, St George's

University of London, London,

Jennifer Tulloch,

St George's University of London.

Denise Coster,

St George's University of London.

Pippa Oakeshott,

Community Health Sciences, St George's

University of London, London.

\section{REFERENCES}

1. Parker E, Glasziou P. Use of evidence in hypertension guidelines: should we measure in both arms? Br J Ger Pract 2009; 59(560): e87-92.

2. McManus RJ, Glasziou P, Hayen A, et al. Blood pressure self-monitoring: questions and answers from a national conference. BMJ 2009; 338(7685): a2732.

3. Williams B, Poulter NR, Brown, et al. Guidelines for the management of hypertension: report of the fourth working party of the British Hypertension Society. BHS guidelines 2004

http://www.bhsoc.org/Latest_BHS_management_Guid elines.stm (accessed 11 May 2009)

4. Kerry S, Markus H, Khong T, et al. Community based trial of home blood pressure monitoring with nurseled telephone support in patients with stroke or transient ischaemic attack recently discharged from hospital. Trials 2008; 9: 15 .

5. Nordmann A, Frach B, Walker T, et al. Reliability of patients measuring blood pressure at home: prospective observational study. BMJ 1999; 319(7218): 1172.

DOI: 10.3399/bjgp09X420969

\section{Hypertension guidelines}

We were interested to read Parker and Glasziou's assessment of previous hypertension guidelines and their advice on the measurement of both arms, to identify an inter-arm difference. ${ }^{1}$ We have also researched this subject, ${ }^{2}$ and found that the advice to measure both arms can be traced back, almost verbatim, over 70 years. ${ }^{3}$ The ESH 2007 guidelines, however, took a significant step in attributing an inter-arm difference to peripheral vascular disease for the first time. ${ }^{4}$ Unfortunately, the weight of evidence supporting this statement was not assessed in that guideline, exemplifying Parker and Glasziou's argument. We have sought clarification of this evidence, but requests to the guideline's authors have not received a response. Consequently, we have been conducting our own systematic review of the evidence associating an inter-arm difference with peripheral vascular disease. Preliminary results of our metaanalysis suggest a significant association of a systolic inter-arm difference $>10 \mathrm{mmHg}$ or $>15 \mathrm{mmHg}$ with peripheral vascular disease $(\mathrm{OR}=5.25,95 \% \mathrm{Cl}=$ 2.85 to 9.70 and $\mathrm{OR}=6.46,95 \% \mathrm{Cl}=$ 